\title{
Penerapan Teknik Mind Mapping, Impersonating dan Questionning dalam Pembelajaran Pidato di SMAN 1 Semaka
}

\author{
The Implementation of Mindmapping, Impersonating and Questionning Technique in \\ teaching speech for SMAN 1 Semaka
}

\author{
Suprayogi Suprayogi ${ }^{1}$, Samanik Samanik ${ }^{2}$, Erani Putri Chaniago ${ }^{3}$ \\ 1,2,3 Program Studi Sastra Inggris, Fakultas Sastra dan Ilmu Pendidikan, Universitas Teknokrat Indonesia, \\ Indonesia \\ e-mail: suprayogi@teknokrat.ac.id*
}

\begin{abstract}
Abstrak
Revolusi Industri 4.0 menuntut siswa-siswi sekolah menengah atas untuk menguasai bahasa Inggris akademis sehingga English Club berperan dalam memperkenalkan lingkungan berbahasa Inggris untuk siswa melalui kegiatan berbicara di depan umum. Akan tetapi, pelatihan intensif sangat dibutuhkan untuk mencapai itu semua. Studi ini bertujuan untuk melaporkan dan menganalisis hasil dari pengabdian masyarakat dalam bentuk pelatihan intensif untuk siswasiswi di SMAN 1 Semaka. Terdapat 12 siswa yang mengikuti pelatihan intensif mindmapping, impersonating dan questioning (MIQ) yang dilaksanakan dalam 10 pertemuan. Keseluruhan pertemuann dilaksanakan daring menggunakan media zoom dan grup whatsapp. Untuk melihat perkembangan dan signifikansi penerapan teknik MIQ, pretest dan post test serta uji statistik deskriptif dilakukan. Secara umum penerapan teknik MIQ signifikan. Studi ini menyimpulkan bahwa teknik ini dapat dijadikan alternatif untuk mengajarkan pidato untuk persiapan kompetisi siswa.
\end{abstract}

Kata kunci- berbicara di depan umum, impersonating, mind mapping, pidato, questioning.

\begin{abstract}
As Industrial revolution 4.0 demands academic English mastery for senior high school students, English Club plays important roles to introduce the students to the academic English environment through public speaking. However, it needs intensive training to achieve it. This study aims at reporting and analyzing the result of community service in the form of intensive speech training for students in SMAN 1 Semaka. Twelve students are involved in the training of mind mapping, impersonating, and questioning (MIQ) technique conducted in 10 meetings. All the activities were held online through zoom and whatsapp group because of COVID 19 pandemic. To see the progress and the significance of the technique, post test and pretest were conducted, then analyzed through descriptive statistics. Overall the result of the technique implementation is significant. This study suggests that MIQ technique can be used as an alternative of teaching speech for competition preparation for students.
\end{abstract}

Keyword-impersonating, mindmapping, public speaking, questioning, speech.

\section{PENDAHULUAN}

Perkembangan bahasa Inggris di kalangan siswa Sekolah Menengah Atas Indonesia saat ini berfokus pada pendekatan berbasis genre di mana siswa belajar keterampilan bahasa Inggris melalui berbagai teks. Harapan dari pendekatan pembelajaran ini adalah siswa mampu menangkap materi otentik dari sumber belajar yang tersedia untuk keterampilan membaca, menulis, menyimak dan berbicara. Namun dalam praktiknya, saat ini permintaan bahasa Inggris untuk pelajar tingkat tersebut terus meningkat terutama di era Revolusi Industri 4.0. Saat ini 
bahasa Inggris merupakan aset yang potensial untuk dikembangkan baik bagi guru maupun pembelajar (Suprayogi \& Pranoto, 2020a). Senada dengan hal tersebut, Miranti, Nurjanah, \& Dwiastuty (2020) juga meyakini bahwa saat ini bahasa Inggris membantu para mahasiswa untuk mempermudah mereka dalam melamar pekerjaan mengingat Bahasa Inggris merupakan salah satu syarat yang harus dimiliki. Lebih jauh lagi, ketika memasuki pendidikan tinggi, siswa diharapkan telah menguasai bahasa Inggris dasar yang terlihat dari kemampuan berbicara dan membaca mereka. Artinya, keterampilan antara bahasa Inggris dan teknologi adalah sebuah keharusan yang dimiliki siswa maupun guru di era ini (Al Falaq, Suprayogi, Nofita, \& Husna, 2021, Suprayogi \& Pranoto, 2020b).

SMA Negeri 1 Semaka merupakan salah satu sekolah yang menjawab kebutuhan bahasa Inggris di era atau Revolusi Industri 4.0. Selain melaksanakan pembelajaran bahasa Inggris seperti sekolah lain melalui pelajaran bahasa Inggris di setiap minggunya, sekolah ini juga menggalakkan kegiatan ekstrakurikuler English Club. Klub Bahasa Inggris ini adalah platform bagi siswa untuk mengembangkan bahasa Inggris mereka ke konteks yang lebih luas dari Bahasa Inggris Akademik di mana mereka dapat memperoleh kosakata baru dan berlatih berbicara di depan umum dalam bahasa Inggris. Melalui berbicara di depan umum, siswa dapat belajar untuk lebih mengungkapkan isu-isu terkini dan berbagai bahasa formal atau akademik. Langkah strategis sekolah ini berhasil dipertahankan agar siswa anggota English Club sadar akan tingkat bahasa Inggris yang harus mereka miliki.

Lokasi sekolah ini cukup jauh dari ibu kota provinsi yaitu sekitar 4 jam; Namun, keberadaan English Club cukup aktif dengan mengirimkan beberapa delegasi ke tingkat kompetisi bahasa Inggris provinsi yang bergengsi dan kompetitif. Beberapa kali mahasiswa berhasil lolos ke babak semifinal (15 besar) atau bahkan final ( 5 besar) di berbagai kompetisi, salah satunya lomba pidato. Beberapa mahasiswa English Club selanjutnya melanjutkan ke Jurusan Bahasa Inggris di beberapa universitas dan melanjutkan karir kompetisi public speaking mereka. English Club juga berjalan dengan baik dalam hal latihan mingguan sehingga motivasi siswa cukup tinggi.

Di tengah upaya yang dilakukan oleh pihak sekolah dan siswa, masih terdapat beberapa keterbatasan yang dihadapi mereka dalam hal akses terhadap sumber belajar yang berdampak langsung pada kinerja belajar dan kompetisi mereka, terutama bagaimana berbicara di depan umum menggunakan bahasa Inggris dan mengkontekstualisasikannya. Selanjutnya, proses dan konten pelatihan belum dikembangkan secara maksimal. Siswa masih kurang menemukan best practice pidato khususnya pidato dadakan. Pidato dadakan adalah pidato yang disampaikan dengan persiapan singkat (Lucas, 2005 dalam Girardelli, Barroero, \& Gu, 2016)). Sistem pelatihan terstruktur masih dikembangkan, dan praktiknya terbatas pada latihan topik acak. Selain masalah-masalah yang telah disebutkan sebelumnya, ada dua masalah lagi yang kemudian menjadi dasar pertimbangan pelaksanaan pengabdian kepada masyarakat di sekolah ini. Di English Club ini, latihan impromptu speech jarang digunakan, sehingga siswa masih mengalami kecemasan. Masalah kedua adalah pengucapan yang menjadi tantangan paling umum sebagai pelajar Bahasa Inggris sebagai Bahasa Asing (EFL).

Untuk mengatasi permasalahan tersebut, pengabdian masyarakat pada pelatihan pidato bagi mahasiswa ini diadakan oleh Univerisitas Teknokrat Indonesia, khususnya dosen dan mahasiswa dari Program Studi Sastra Inggris. Melihat bahwa pelatihan pidato itu luas, maka ada tiga materi yang menjadi fokus yaitu mind mapping, impersonating dan questioning, yang kemudian disebut sebagai teknik MIQ.

\section{METODE PELAKSANAAN}

Pengabdian kepada masyarakat ini dilakukan dalam bentuk pelatihan pidato di SMAN 1 Semaka Kabupaten Tanggamus Provinsi Lampung, tepatnya berada di Jalan Alim Ulama Karangrejo, Kecamatan Semaka Kabupaten Tanggamus. Jarak dari sekolah ke kampus penulis, Universitas Teknorat Indonesia, berjarak $116 \mathrm{~km}$. Ada 12 siswa yang menjadi peserta pelatihan. Mereka adalah siswa di divisi pidato English Club SMAN 1 Semaka, kelas X dan 
XI.Dikarenakan kondisi COVID-19, kegiatan PkM dilakukan secara full online dengan menggunakan platform zoom conference dan grup whatsapp. Ada 10 kegiatan utama dalam rangkaian latihan pidato ini.

a. Kegiatan 1 adalah pengenalan dan pre-test. Pada tahap ini, tim PkM memperkenalkan tujuan pelatihan kepada siswa dan menantang siswa untuk melakukan pretest dalam hal komposisi pidato dan pengiriman 2-3 menit di mana siswa mengirim video ke whatsapp dalam tiga hari ke depan.

b. Kegiatan 2 adalah analisis pre-test untuk mengetahui titik awal kemampuan mereka dalam berbicara sebelum diberikan pelatihan.

c. Kegiatan 3 adalah webinar zoom tentang "kesalahan umum dalam lomba pidato" dilanjutkan dengan sesi tanya jawab serta pembahasan pre-test. Melalui kegiatan ini diharapkan siswa tidak mengulangi kesalahan yang sama dan fokus pada pengembangan kekuatan bicaranya.

d. Kegiatan 4-5 berfokus pada praktik teknik mindmapping. Dalam kegiatan ini, siswa dilatih untuk melakukan penggalian informasi dan mengkontekstualisasikan topik pidato. Para siswa dihadapkan pada "argumen positif - negatif", "sebab dan akibat", "pihak yang terlibat", "solusi saat ini - solusi alternatif"

e. Kegiatan 6-7 berfokus pada teknik impersonating. Dalam kegiatan ini siswa melakukan vrbatimming atau mentranskrip video pidato dari Youtube kemudian berlatih menirukan penampilan pembicara.

f. Kegiatan 8-9 adalah teknik questionnning di mana siswa fokus pada pertanyaan apa yang harus dijawab ketika mereka mendapatkan topik serta hal-hal apa yang menjadi poin tambahan untuk konten. Kegiatan ini juga melatih siswa untuk menjawab pertanyaan spontan.

g. Kegiatan terakhir dari kegiatan 10 adalah sesi penutup dimana siswa ditantang untuk merevisi pidato awal mereka dengan menerapkan teknik MIQ. Mereka mengirimkan video ke whatsapp kemudian dievaluasi.

Indikator keberhasilan ini diukur dari nilai pretest dan post- test, dan siswa dianggap berhasil apabila memiliki kenaikan nilai.

\section{HASIL DAN PEMBAHASAN}

Lutfiana (2005) menyatakan bahwa lomba pidato membantu siswa untuk menunjukkan bakat mereka dan membuat siswa bekerja lebih keras serta mengurangi perasaan negatif yang mungkin terjadi pada siswa tersebut. Salah satu upaya untuk mengungkapkan potensi siswa dalam berbicara bahasa Inggris di depan umum adalah dengan memberikan mereka pelatihan intensif, dalam konteks ini adalah teknik MIQ (mind mapping, impersonating dan questioning).

\section{Kegiatan Mind Mapping}

Menurut Budd (2004, dalam (Buran \& Filyukov, 2015) mind mapping adalah garis besar penguraian ide-ide dari ide sentral ke kategori-kategori yang lebih kecil dengan cabangcabang yang lebih besar. Dalam menerapkan teknik mind mapping, pada awalnya siswa bingung bagaimana cara menulis di selembar kertas kosong. Oleh karena itu, pelatih memberikan contoh bagaimana melakukan mind mapping dalam pidato. Pelatih mensimulasikan teknik mind mapping dengan memberikan topik pidato tentang "my future success", dan kemudian menuliskan beberapa balon poin seperti "defining success", "measuring individual sucess", "what success means to me", dan "jokes speech" atau pidato humor. Memasukkan unsur humor dalam pengajaran bahasa menjadi penting Pranoto \& Suprayogi (2020), dan bagaimana siswa dapat menyampaikan humor dalam bahasa Inggris dalam konteks pidato menjadi hal yang penting untuk diperkenakan. Setelah itu, siswa diberi kesempatan untuk melakukan pemetaan sendiri pada topik yang berbeda dalam 20 menit dan membagikannya satu per satu sesuai giliran. Untuk menjaga kondisi kelas tetap kondusif, instruktur telah memastikan bahwa siswasiswi berada dalam kondisi belajar yang menyenangkan, dimana hal ini sejalan dengan Recard

Penerapan Teknik Mind Mapping, Impersonating dan Questionning dalam Pembelajaran Pidato di SMAN 1 Semaka (Suprayogi Suprayogi, Samanik Samanik, Erani Putri Chaniago) 
\& Nathania (2021) bahwa guru atau pelatih dapat mengoreksi perilaku siswa dengan cara yang menyenangkan.

Teknik mind mapping dinilai sangat membantu siswa dalam menentukan isi pidato yang akan disampaikan. Konten menjadi poin penting yang harus ditonjolkan dalam pelatihan ini karena itu mereka diberikan dasar mindmapping terutama dalam aspek mendapatkan contoh dari pengalaman hidup mereka sehari-hari. Kemudian, siswa juga dihadapkan pada isi pengalaman hidup orang lain dan pembelajaran dari pengalaman tersebut. Dalam konteks lomba pidato, pengembangan konten atau materi dihitung 30\% dari total skor pidato. Setelah melakukan kegiatan mindmapping, siswa diberi pekerjaan rumah untuk melakukan kegiatan mindmapping pada topik lain.

\section{Kegiatan Impersonating}

Dalam pelaksanaan kegiatan impersonating atau meniru, siswa tidak hanya melakukan kegiatan diskusi tetapi juga menonton video. Para siswa pada awalnya diberikan penjelasan tentang konsep impersonating. Pada sesi ini, siswa disuguhi contoh video pidato singkat kemudian diberikan naskah pidato. Setelah itu, siswa berlatih pengucapan serta intonasi dari video tersebut. Puncak latihan pengucapan dilakukan mengingat siswa adalah pembelajar EFL. Silalahi (2016) percaya bahwa salah pengucapan dapat menyebabkan kesalahpahaman makna dalam komunikasi. Siswa diperkenalkan ke Cambridge Dictionary versi online di mana mereka dapat memiliki model pengucapan yang diharapkan. Jadi, dengan memperkenalkan ini dalam pelatihan, siswa dapat memeriksa sendiri pengucapannya dengan membuka halaman kamus online. L angkah selanjutnya dari peniruan adalah melihat bahasa tubuh pembicara. Siswa diminta memperhatikan kontak mata, isyarat tangan, dan ekspresi wajah pembicara. Pada langkah ini, siswa diberi pekerjaan rumah dengan merekam video diri mereka yang meniru video pidato sebelumnya. Tujuan dari kegiatan ini adalah untuk membuat siswa sadar akan performa pidato yang diharapkan dengan versi terbaik dari kinerja mereka sebagai ESL.

Hasil penampilan mereka dalam menirukan tuturan beragam. Dengan menggunakan aplikasi perekaman video ponsel, mereka merekam video penampilan berpidato selama 3 menit. Beberapa dari mereka mampu meningkatkan kesadaran bahasa tubuh mereka terutama dalam nada suara, gerakan tangan dan ekspresi wajah seperti pembicara dalam video. Namun, dari segi pengucapan, beberapa siswa masih kesulitan mengucapkan beberapa kata yang jarang mereka gunakan.

\section{Kegiatan Questionning}

Selain mindmapping dan impersonating, teknik bertanya adalah keterampilan lain yang dilatihkan kepada siswa. Hal ini untuk melatih kemampuan impromptu speech mereka. Seperti yang dikemukakan Angraini (2016), keterampilan berbicara di depan umum tidak dapat dicapai secara otomatis sehingga latihan yang tepat dan kepercayaan diri adalah kuncinya. Dengan demikian latihan ini merupakan bagian dari latihan yang ditargetkan untuk juga melatih kepercayaan diri mereka dengan memiliki banyak konten untuk dipersiapkan. Siswa diberi 7 pertanyaan dasar dalam membangun ide pidato: "apa itu (topik)?", "mengapa (topik) mendesak untuk dibahas?", "seberapa umum orang melihat (topik)", "apa solusi saat ini dalam kaitannya dengan (topik)?", "mengapa solusi itu (dalam topik) tidak cukup", "apa ide baru untuk (topik) Anda?", "kata-kata apa yang Anda inginkan dari mereka untuk diingat di akhir pidato Anda?". Pertanyaan tingkat kedua adalah siswa bertanya kepada temannya dengan pertanyaan "mengapa?" dan bagaimana?" pertanyaan. Kedua pertanyaan ini diajukan setelah siswa lain menyampaikan pidato. Melalui latihan memberikan soal-soal tersebut, mereka dilatih untuk berpikir secara dadakan sehingga secara bertahap dapat meningkatkan kefasihan mereka.

Setelah mendapatkan 7 strategi pertanyaan dan strategi pertanyaan mengapabagaimana, siswa mampu menyusun pidato dengan lebih baik. Siswa dapat mengidentifikasi setiap poin dan memberikan elaborasi pada konten yang ingin mereka sampaikan. Dalam kegiatan ini, mereka diberikan waktu satu jam untuk mempersiapkan pidato dengan menggunakan strategi tersebut. Setelah itu, mereka melakukan performance dengan menggunakan draft yang telah mereka siapkan dan diberikan pertanyaan dari rekan-rekan mereka. Sebagian besar dari mereka membutuhkan waktu yang lama untuk merumuskan 
jawaban dan beberapa siswa mampu menjawab pertanyaan. Praktek ini tidak dapat dilihat dalam satu kali pertemuan. Setidaknya mereka tahu dasar bagaimana melakukan praktik di masa depan ketika tim pengabdian masyarakat menyelesaikan program.

Girardelli et al., (2016) menjelaskan bagaimana pidato dadakan merupakan sesi yang menakutkan bagi siswa karena siswa merasa tertekan secara emosional yang membuat siswa cemas. Senada dengan hal tersebut, (Anandari, 2015) mengungkapkan bahwa kecemasan berbahasa asing disebabkan oleh tiga faktor yaitu ketakutan, rasa malu dan ketidaknyamanan. Andari menambahkan, kegiatan refleksi bersama dapat membantu mengurangi kecemasan tersebut sehingga dapat diketahui kelebihan dan kekurangan siswa. Berkaitan dengan konteks ini, kegiatan refleksi dan kegiatan teman sebaya menjadi poin penting untuk diberikan di setiap sesi karena mengurangi kecemasan mereka bahwa mereka tidak sendirian menghadapi tantangan untuk meningkatkan bahasa Inggris mereka yang lebih baik.

Selain perhitungan statistik untuk melihat signifikansi kegiatan serta penjelasan deskriptif tentang bagaimana teknik MIQ mempengaruhi kinerja siswa, artikel ini juga menjelaskan dampak lain dari kegiatan pengabdian masyarakat ini kepada siswa. Siswa menjadi termotivasi karena sudah diberikan sumber bahan dan strategi untuk melakukan penambangan bahan. Mereka juga dapat mengatur pertemuan konferensi dan pengiriman dokumen whatsapp sendiri. Hal ini menunjukkan bahwa literasi teknologi pada siswa juga meningkat

\section{Dampak Penerapan MIQ pada Penampilan Pidato Siswa}

Berikut adalah hasil pre-test 12 siswa divisi pidato English Club SMAN 1 Semaka. Para mahasiswa mengirimkan link video tersebut ke grup whatsapp yang terdiri dari tim pengabdian masyarakat Universitas Teknokrat Indonesia, 12 mahasiswa dan 1 orang guru atau pembina English Club.

Tabel 1. Hasil Pre-test Siswa

\begin{tabular}{lllllll}
\hline No & $\begin{array}{l}\text { Nama } \\
\text { Siswa }\end{array}$ & $\begin{array}{l}\text { English } \\
(\mathbf{2 0})\end{array}$ & $\begin{array}{l}\text { Expression } \\
(\mathbf{2 0})\end{array}$ & $\begin{array}{l}\text { Content } \\
(\mathbf{3 0})\end{array}$ & $\begin{array}{l}\text { Message } \\
(\mathbf{3 0})\end{array}$ & $\begin{array}{l}\text { Total Pre- } \\
\text { Test }\end{array}$ \\
\hline 1 & R V & 12 & 12 & 15 & 16 & 55 \\
\hline 2 & F S & 13 & 12 & 15 & 16 & 56 \\
\hline 3 & S P & 12 & 12 & 15 & 15 & 54 \\
\hline 4 & S H & 13 & 13 & 14 & 14 & 55 \\
\hline 5 & S J & 12 & 11 & 14 & 14 & 52 \\
\hline 6 & L H & 11 & 11 & 14 & 15 & 51 \\
\hline 7 & D A & 11 & 12 & 14 & 16 & 53 \\
\hline 8 & A A & 12 & 12 & 15 & 16 & 55 \\
\hline 9 & Y S & 12 & 12 & 14 & 16 & 54 \\
\hline 10 & A S & 12 & 12 & 13 & 15 & 53 \\
\hline 11 & N A & 11 & 12 & 14 & 16 & 53 \\
\hline 12 & S O & 11 & 11 & 13 & 15 & 50 \\
\hline
\end{tabular}

Ada empat aspek penilaian yaitu Bahasa Inggris (Pengucapan dan Kosakata), Ekspresi (Bahasa tubuh, intonasi, dan ekspresi wajah), isi dan pesan ucapan. Aspek-aspek ini juga terlihat setelah Teknik MIQ diberikan. Berikut adalah hasil post test yang dapat dilihat pada Tabel 2.

Tabel 1. Hasil Post-test Siswa

\begin{tabular}{lllllll}
\hline No & $\begin{array}{l}\text { Nama } \\
\text { Siswa }\end{array}$ & $\begin{array}{l}\text { English } \\
(\mathbf{2 0})\end{array}$ & $\begin{array}{l}\text { Expression } \\
(\mathbf{2 0})\end{array}$ & $\begin{array}{l}\text { Content } \\
(\mathbf{3 0})\end{array}$ & $\begin{array}{l}\text { Message } \\
(\mathbf{3 0})\end{array}$ & $\begin{array}{l}\text { Total Pre- } \\
\text { Test }\end{array}$ \\
\hline 1 & R V & 15 & 15 & 17 & 18 & 65 \\
\hline 2 & F S & 15 & 14 & 16 & 18 & 62 \\
\hline 3 & S P & 15 & 13 & 16 & 16 & 60 \\
\hline 4 & S H & 15 & 16 & 16 & 17 & 64 \\
\hline 5 & S J & 16 & 17 & 17 & 17 & 67 \\
\hline 6 & L H & 14 & 14 & 15 & 16 & 59 \\
\hline 7 & D A & 14 & 14 & 16 & 18 & 62 \\
\hline 8 & A A & 16 & 15 & 18 & 18 & 67 \\
\hline 9 & Y S & 15 & 15 & 16 & 19 & 65 \\
\hline
\end{tabular}




\begin{tabular}{lllllll}
\hline 10 & A S & 14 & 14 & 16 & 18 & 62 \\
\hline 11 & N A & 14 & 14 & 15 & 18 & 61 \\
\hline 12 & S O & 14 & 15 & 16 & 17 & 62 \\
\hline
\end{tabular}

Setelah diperoleh hasil pre-test dan post-test, selanjutnya dilakukan pengukuran statistik deskriptif dimana hasilnya dapat dilihat pada tabel berikut yang meliputi 8 aspek, dari mean sampai sum.

Tabel 3. Hasil Perhitngan Statistik Deskriptif

\begin{tabular}{lll}
\hline Aspect & Pre-test & Post-test \\
\hline Mean & 53.42 & 63 \\
\hline Standard Error & 0.51 & 0.749 \\
\hline Median & 53.5 & 62 \\
\hline Mode & 55 & 62 \\
\hline Standard Deviation & 1.78 & 2.59 \\
\hline Minimum & 50 & 59 \\
\hline Maximum & 56 & 67 \\
\hline Sum & 641 & 756 \\
\hline
\end{tabular}

Tabel tersebut menunjukkan bahwa ada peningkatan yang signifikan pada skor kinerja berbicara siswa pada pre-test dan post-test dalam hal bahasa Inggris, ekspresi, isi dan pesan mereka. Rentang peningkatan untuk kedua belas peserta adalah rata-rata 9,58 poin, skor minimum 9 poin dan skor maksimum 11 poin.

\section{KESIMPULAN}

Setelah menerapkan teknik mind mapping, impersonating dan questioning (MIQ), artikel ini menyimpulkan bahwa MIQ dapat digunakan sebagai alternatif pembelajaran pidato bagi siswa, khususnya siswa yang dipersiapkan untuk mengikuti kompetisi public speaking bahasa Inggris. Teknik ini memberikan kesempatan belajar untuk berpikir banyak dalam menemukan ide-ide baru untuk disampaikan, sehingga memungkinkan mereka untuk menghubungkan titik-titik pengetahuan, pengalaman, dan logika mereka. Ini lebih lanjut memberi mereka model pengucapan yang diharapkan dan gerakan meyakinkan dalam penyampaian. Dengan dilaksanakannya rangkaian kegiatan inti MIQ, penelitian ini mampu memberikan latihan mandiri bagi siswa dalam arti selama siswa memiliki motivasi untuk belajar pidato, teknik MIQ dapat diterapkan untuk topik lain dengan atau tanpa instruktur. Melalui pelaksanaan kegiatan ini, di masa COVID-19 atau hambatan geografis, whatsapp group dan video conference zoom menjadi solusi alternatif yang membantu pelaksanaan program berjalan dengan baik selama jangkauan internet di wilayah tersebut terjalin.

\section{UCAPAN TERIMAKASIH}

Terimakasih kepada Universitas Indonesia atas Pendanaan Hibah PkM Internal Tahun 2020.

\section{DAFTAR PUSTAKA}

Al Falaq, J. S., Suprayogi, S., Nofita, F. N., \& Husna, A. U. (2021). Exploring The Potentials of Wattpad For Literature Class. Indonesian Journal of Learning Studies, 1(2), 12-19.

Anandari, C. L. (2015). Indonesian EFL Students' Anxiety in Speech Production: Possible Causes and Remedy. TEFLIN Journal - A Publication on the Teaching and Learning of English, 26(1), 1. https://doi.org/10.15639/teflinjournal.v26i1/1-16

Angraini, Y. (2016). Rules of Three Analysis in Persuasive Public Speaking Presentation. ANGLO-SAXON: Jurnal Ilmiah Program Studi Pendidikan Bahasa Inggris, 7(1), 3. https://doi.org/10.33373/anglo.v7i1.542

Buran, A., \& Filyukov, A. (2015). Mind Mapping Technique in Language Learning. XV 
International Conference "Linguistic and Cultural Studies: Traditions and Innovations, 206(November), 215-218. https://doi.org/10.1016/j.sbspro.2015.10.010

Girardelli, D., Barroero, P., \& Gu, T. (2016). Gamifying Impromptu Speech for ESL/EFL Students. 18-25. https://doi.org/10.4995/head16.2016.2431

Lutfiana, R. (2005). SPEECH CONTEST TO IMPROVE STUDENTS' FLUENCY IN SPEAKING. Jurnal Ilmiah Bahasa Dan Sastra, 3(2), 25-27.

Miranti, I., Nurjanah, N., \& Dwiastuty, N. (2020). Penggunaan Permainan dalam Pengajaran Bahasa Inggris bagi Guru-Guru Madrasah Ibtidaiyah Muta'alimin dan Madrasah Ibtidaiyah Hidayatul Mubtadi'in. Jurnal PkM Pengabdian Kepada Masyarakat, 3(3), 273. https://doi.org/10.30998/jurnalpkm.v3i3.6839

Pranoto, S. E., \& Suprayogi, S. (2020). Incorporating 9GAG Memes to Develop EFL Learners' Speaking Ability and Willingness to Communicate. IJEE (Indonesian Journal of English Education), 7(2), 130-144. https://doi.org/10.15408/ijee.v7i2.17496

Recard, M., \& Nathania, Y. H. (2021). The Implementation and the Impact of Attention Grabbers in Young Learners' Classrooms: A Case Study. Teknosastik, 19(1), 1. https://doi.org/10.33365/ts.v19i1.586

Silalahi, R. M. P. (2016). Pronunciation Problems of Indonesian EFLLearners: Analysis. Journal of English Language and Culture, 147(2), 11-40.

Suprayogi, S., \& Pranoto, B. E. (2020a). Students' Perspectives Toward News Voiceover Activity in Pronunciation Class. Proceedings of the Twelfth Conference on Applied $\begin{array}{llll}\text { Linguistics } & \text { (CONAPLIN 2019), }\end{array}$ https://doi.org/10.2991/assehr.k.200406.041

Suprayogi, S., \& Pranoto, B. E. (2020b). Virtual Tourism Exhibition Activity in English for Tourism Class: Students' Perspectives. Celtic: A Journal of Culture, English Language Teaching, Literature and Linguistics, $7(2), \quad 199-207$. https://doi.org/10.22219/celtic.v7i2.14064 